\title{
SOBREMESAS LÁCTEAS SABOR CHOCOLATE E BARU (Dipteryx Alata Vogel): DESENVOLVIMENTO E CARACTERIZAÇÃO
}

\author{
P. N. CRUZ ${ }^{1}$, P.B. PERTUZATTI ${ }^{2}$ \\ ${ }^{1}$ Universidade Federal de Santa Catarina, Departamento de Engenharia de Alimentos \\ ${ }^{2}$ Universidade Federal de Mato Grosso, Departamento de Engenharia Alimentos \\ E-mail para contato: pollyannaicm@hotmail.com
}

\begin{abstract}
RESUMO - A indústria láctea vem lançando novos produtos e dentre eles estão as sobremesas lácteas. A adição de baru é uma opção interessante, pois podem agregar valor nutricional ao produto, já que seu óleo possui alto teor de ácido linoleico e a castanha elevado teor de minerais. O trabalho teve como objetivo a utilização de um planejamento experimental para o desenvolvimento de formulações de sobremesa láctea de chocolate e baru. Foi realizado um delineamento composto central rotacional com 2 variáveis independentes, incluindo 4 pontos axiais e 3 repetições no ponto central. Nos ensaios das sobremesas lácteas foram analisados os teores de fibras, lipídeos, cinzas, umidade, $\mathrm{pH}$, e acidez. Os resultados obtidos mostraram que os parâmetros estavam de acordo com a literatura e por intermédio do experimento fatorial foi possível prever o comportamento das sobremesas e medir o efeito da utilização das diferentes concentrações de chocolate e baru, bem como a interação entre eles em toda faixa avaliada.
\end{abstract}

\section{INTRODUÇÃO}

A sociedade brasileira vem passando por um intenso processo de transformação, a exemplo de outros países, tem havido uma mudança significativa nos hábitos de consumo. Essas mudanças caminham na direção da valorização do tempo das pessoas. Sendo assim, justificado o desenvolvimento de um produto de fácil manuseio e que atenda às necessidades específicas desta clientela atual.

De acordo com Nunes et al. (1998), as sobremesas lácteas prontas para comer, com vida de prateleira média, apresentaram importante crescimento nas últimas décadas. Os ingredientes inovadores e os sistemas tecnológicos aplicados nas fábricas de laticínios têm proporcionado novas alternativas às sobremesas lácteas, permitindo a produção de sobremesas com novos sabores, com maior digestibilidade e maior valor nutritivo.

O uso do baru em produtos alimentícios ainda é muito baixo, criar novas alternativas para o enriquecimento funcional de sobremesas lácteas, proporciona benefícios econômicos, nutricionais e ambientais. O desenvolvimento dessas sobremesas com a utilização da castanha do baru pode constituir uma alternativa tecnológica para agregar valor funcional à elas. 
Este trabalho teve por objetivo o desenvolvimento de formulações de sobremesas lácteas de chocolate e amêndoa do baru, através de um planejamento experimental $2^{2}$, tendo como variáveis resposta as análises físico-químicas $\mathrm{pH}$, acidez, umidade, cinza, lipídeos e fibras.

\section{MATERIAL E MÉTODOS}

Foram utilizadas amêndoas de baru, obtidas na região de Pontal do Araguaia - MT. As amêndoas foram colhidas no estádio de maturação madura e foram acondicionadas no Laboratório de Análise de Alimentos, da Universidade Federal de Mato Grosso, até a realização das análises.

As formulações utilizadas neste trabalho foram compostas pelos seguintes ingredientes: leite $(43 \%)$, açúcar $(18 \%)$, creme de leite $(17 \%)$, goma guar $(0,5 \%)$, sorbato de potássio $(0,08 \%)$, chocolate, amêndoa do baru e água que foi utilizada como quantidade suficiente para a análise (QSA), para completar $100 \%$ da formulação. As variáveis independentes do planejamento do experimento foram o chocolate e o baru, e elas variaram de acordo com o planejamento experimental utilizado, com duas variáveis independentes, adicionado de quatro pontos axiais e três repetições no ponto central.

Após a adição dos ingredientes foi realizada a agitação para obter a correta distribuição dos componentes da massa e esta foi submetida a aquecimento durante 6 minutos. Posteriormente, acondicionadas em embalagens de vidro e em seguida, elas foram resfriadas a $4{ }^{\circ} \mathrm{C}$ durante todo o decorrer das análises.

Para a obtenção das diferentes formulações das sobremesas foi utilizado um delineamento fatorial completo $2^{2}$ composto, perfazendo onze ensaios. As variáveis e os níveis codificados e reais do planejamento estão apresentados na Tabela1.

Tabela 1 - Variáveis e níveis do planejamento experimental completo $2^{2}$

\begin{tabular}{lccccc}
\hline & $-\alpha$ & \multicolumn{4}{c}{ Níveis codificados } \\
\cline { 2 - 6 } & $-1,41$ & -1 & 0 & +1 & $+1,41$ \\
\cline { 2 - 6 } Variáveis & \multicolumn{5}{c}{ Níveis reais dos ingredientes } \\
Independentes & \multicolumn{5}{c}{. } \\
Chocolate $(\%)$ & 4 & 5,45 & 9 & 12,55 & 14 \\
Baru (\%) & 0 & 2,04 & 7 & 11,96 & 14 \\
\hline
\end{tabular}

\section{RESULTADOS E DISCUSSÃO}

Na tabela 2 encontram-se os valores obtidos nos parâmetros físicos-químicos das sobremesas lácteas de chocolate e baru. Os resultados das análises das sobremesas foram expressos através de média e desvio padrão.

Tabela 2 - Valores médios dos parâmetros físico-químicos em sobremesas lácteas. 


\begin{tabular}{|c|c|c|c|c|c|c|}
\hline Ensaios & $\mathbf{p H}$ & Acidez & Umidade & Cinzas & Lipídeos & Fibras \\
\hline 1 & $6,76 \pm 0,01^{\mathrm{c}}$ & $2,30 \pm 0,16^{\mathbf{f}}$ & $44,7 \pm 2,22^{b}$ & $0,75 \pm 0,02^{\mathbf{b}}$ & $8,97 \pm 0,45^{\mathbf{c}}$ & $0,69 \pm 0,03^{\mathbf{b c}}$ \\
\hline 2 & $6,80 \pm 0,01^{\mathbf{b}}$ & $3,74 \pm 0,11^{\text {be }}$ & $31,44 \pm 0,24^{\mathbf{d}}$ & $1,08 \pm 0,01^{\text {ef }}$ & $9,79 \pm 0,33^{\mathbf{b}}$ & $1,32 \pm 0,34^{\text {bcd }}$ \\
\hline 3 & $6,45 \pm 0,01^{\mathrm{e}}$ & $3,97 \pm 0,16^{\mathbf{a e}}$ & $28,87 \pm 1,28^{\mathbf{d}}$ & $1,09 \pm 0,03^{\mathrm{e}}$ & $11,36 \pm 0,13^{\mathbf{d h}}$ & $1,94 \pm 0,34^{\mathbf{a d}}$ \\
\hline 4 & $6,52 \pm 0,01^{\mathrm{g}}$ & $2,45 \pm 0,10^{\mathbf{f}}$ & $23,76 \pm 0,81^{\mathbf{f}}$ & $1,31 \pm 0,01^{\mathbf{a}}$ & $12,74 \pm 0,32^{\mathrm{e}}$ & $2,69 \pm 0,03^{\mathbf{a}}$ \\
\hline 5 & $6,53 \pm 0,01^{\mathrm{fg}}$ & $2,59 \pm 0,11^{\mathrm{df}}$ & $39,43 \pm 0,63^{c}$ & $0,85 \pm 0,02^{\mathbf{d}}$ & $12,64 \pm 0,51^{\text {ef }}$ & $1,42 \pm 0,15^{\mathrm{cd}}$ \\
\hline 6 & $6,64 \pm 0,01^{d}$ & $3,95 \pm 0,65^{\text {ae }}$ & $24,14 \pm 0,57^{\mathbf{f}}$ & $1,17 \pm 0,02^{\mathrm{c}}$ & $10,88 \pm 0,18^{\mathbf{d}}$ & $1,57 \pm 0,05^{\mathrm{d}}$ \\
\hline 7 & $6,93 \pm 0,01^{\mathbf{a}}$ & $2,44 \pm 0,05^{\mathbf{f}}$ & $50,08 \pm 0,46^{\mathbf{a}}$ & $0,89 \pm 0,02^{\mathbf{d}}$ & $12,14 \pm 0,06^{\text {efg }}$ & $0,54 \pm 0,21^{\mathbf{b}}$ \\
\hline 8 & $6,55 \pm 0,01^{\mathrm{f}}$ & $4,42 \pm 0,21^{\mathbf{a}}$ & $23,38 \pm 0,45^{\mathbf{f}}$ & $1,23 \pm 0,01^{\mathrm{c}}$ & $13,92 \pm 0,07^{\mathbf{a}}$ & $2,41 \pm 0,73^{\mathbf{a}}$ \\
\hline 9 & $6,60 \pm 0^{\mathbf{h}}$ & $2,96 \pm 0,03^{\text {cdf }}$ & $34,77 \pm 0,62^{e}$ & $1,02 \pm 0,03^{\text {fg }}$ & $11,87 \pm 0,06^{\mathbf{g h}}$ & $1,42 \pm 0,07^{\mathbf{c d}}$ \\
\hline 10 & $6,60 \pm 0,02^{h}$ & $3,33 \pm 0,03^{\text {bce }}$ & $35,48 \pm 0,49^{\mathbf{e}}$ & $1,03 \pm 0,03^{\text {efg }}$ & $11,90 \pm 0,10^{\text {fgh }}$ & $1,40 \pm 0,04^{\mathbf{c d}}$ \\
\hline 11 & $6,61 \pm 0,02^{h}$ & $3,14 \pm 0,12^{\text {bcd }}$ & $34,75 \pm 1,04^{\mathrm{e}}$ & $0,99 \pm 0,03^{\mathrm{g}}$ & $11,93 \pm 0,07^{\mathbf{f g h}}$ & $1,44 \pm 0,01^{\text {cd }}$ \\
\hline
\end{tabular}

Médias seguidas por letras minúsculas diferentes na mesma coluna indicam que existe diferença significativa a $\mathrm{p}<$ 0,05 pelo teste de tukey.

As formulações das sobremesas lácteas apresentaram valores de $\mathrm{pH}$ que variaram de $6,45 \mathrm{a}$ 6,93 , onde o maior valor foi da formulação $7(6,93)$ que diferiu estatisticamente em $p \leq 0,05$ das demais amostras, observou-se que a formulação com o maior $\mathrm{pH}$ (formulação 7), era a única que não continha baru, o que sugere que a presença de baru na sobremesa, diminuiu o $\mathrm{pH}$ da mesma.

Os valores encontrados para as sobremesas de chocolate e baru foram superiores ao valor de 5,15 obtido no trabalho de Henrique et al., (2009) em sobremesa láctea enriquecida com casca de maracujá, porém próximas ao valores encontrados por Nikaedo, Amaral e Penna (2004), em sobremesas lácteas cremosas elaboradas com concentrado proteico de soro e misturas de gomas carragena e guar $(5,77-7,15)$.

Para os valores de acidez, o maior valor foi do ensaio 8 (4,42\%), diferindo estatisticamente dos ensaios 1, 2, 4, 5, 7, 9, 10 e 11 os quais apresentaram menores valores. O teor de acidez dos ensaios das sobremesas lácteas variou de 2,30 a 4,42\%. Valores de 2,51 até 3,37\%, considerados semelhantes, foram encontrados por Henrique et al., (2009) em sobremesas lácteas com a utilização do maracujá integral.

As sobremesas lácteas apresentaram teores de umidade de 23,38 a 50,08\%, onde o maior valor foi da sobremesa $7(50,08 \%)$ que diferiu estatisticamente das outras amostras a $\mathrm{p} \leq 0,05$. Os valores encontrados foram inferiores aos encontrados por Henrique et al., (2009) que constataram teores de 65,15 - 68,22\% de umidade em sobremesas lácteas tipo flan adicionada de maracujá 
integral. Por outro lado, no trabalho de Soler et al., (2011), resultados mais próximos foram encontrados em sobremesas lácteas achocolatadas com abacate ( 42,85-57,86\% de umidade).

Para os valores de cinzas, o maior valor foi do ensaio $4(1,31 \%)$,constituído pelos pontos máximos do planejamento fatorial, diferindo estatisticamente em $\mathrm{p} \leq 0,05$ dos demais ensaios. Os teores de cinzas variaram de 0,85 a $1,31 \%$, sendo superior aos valores $0,46-0,73 \%$ constatado por Henrique et al., (2009) em sobremesas lácteas tipo flan utilizando maracujá integral. A porcentagem do ensaio com o maior teor de cinzas $(1,31 \%)$ foi igual ao constatado por Santana (2011) em iogurtes à base de pitaia, enriquecido com quinoa e sucralose.

As sobremesas apresentaram altos teores de lipídeos que variaram de 8,97 a 13,92\%. O ensaio 8 possui a maior quantidade de baru e apresentou o maior teor de lipídeos (13,92\%), diferindo estatisticamente das demais amostras a $\mathrm{p} \leq 0,05$. Pode-se atribuir o alto teor de lipídios do ensaio 8, à maior adição de baru na formulação, já que a amêndoa contém um alto teor de lipídeos, cerca de $42 \%$, sendo considerada boa fonte energética, além de possuir um elevado grau de insaturação e teor relativamente alto de ácido linoleico, sendo benéfica à saúde (OliveiraSousa et al., 2011). Observa-se também que quando comparado o teor de lipídeos deste trabalho, com outros estudos, valores inferiores de lipídeos, 4,60-8,46\%, foram encontrados por Soler et al., (2011) em sobremesas lácteas achocolatadas com abacate.

As formulações analisadas obtiveram valores que variaram de 0,54 a 2,69 \% de fibra bruta. Os ensaios 3, 4 e 8 obtiveram as maiores médias, não diferindo estatisticamente entre si a $\mathrm{p} \leq$ 0,05. Dados sobre o teor de fibra bruta em sobremesas lácteas, são escassos, Santana (2011) encontrou $1,88 \%$ de fibra alimentar em iogurte à base de pitaia, valor semelhante a 1,94\% da formulação 3, aquela com o nível mínimo de chocolate e máximo de baru. Observou-se que as sobremesas com maiores concentrações de baru obtiveram maiores teores de fibras, demonstrando que a amêndoa do baru pode ter um considerável teor de fibras.

Além das interpretações individuais dos resultados, por intermédio do experimento fatorial $2^{2}$, foi possível prever o comportamento das sobremesas e medir o efeito da utilização das diferentes quantidades de chocolate e baru, bem como a interação entre eles em toda a faixa avaliada. Para as respostas acidez, umidade e lipídeos nenhum efeito linear (L), quadrático (Q) ou de interação apresentou significância estatística $(\mathrm{p} \leq 0,05)$, não interferindo nos resultados das análises. Já para as respostas $\mathrm{pH}$, cinzas e fibras, observou-se que houve efeitos significativos. Como o $\mathrm{R}^{2}$ apresentou valores 98,5; 98,56 e 94,31(\%) respectivamente para $\mathrm{pH}$, cinzas e fibras, foi possível gerar a ANOVA (Análise de Variância), pois mais de $95 \%$ da variabilidade das respostas puderam ser explicadas pelos modelos.

Para a resposta $\mathrm{pH}$, com a ANOVA observou-se que o modelo experimental foi válido para fins preditivos $\left(Y=6,60+0,07 X_{1}-0,29 X_{2}+0,13 X_{2}^{2}\right.$, sendo $X_{1}=$ chocolate, $X_{2}=$ baru e $X_{2}^{2}=$ $\left.\operatorname{Baru}^{2}\right)$, pois a regressão gerada foi significativa onde o $F$ calulado $(120,06)$ foi maior que o $F$ tabelado $(4,35)$ e a falta de ajuste não foi significativa porque o $\mathrm{F}$ calculado $(2,9511)$ apresentouse menos que o F tabelado (19,3). Assim, o modelo foi considerado adequado, sendo possível descrever a superfície de resposta (Figura 1). 


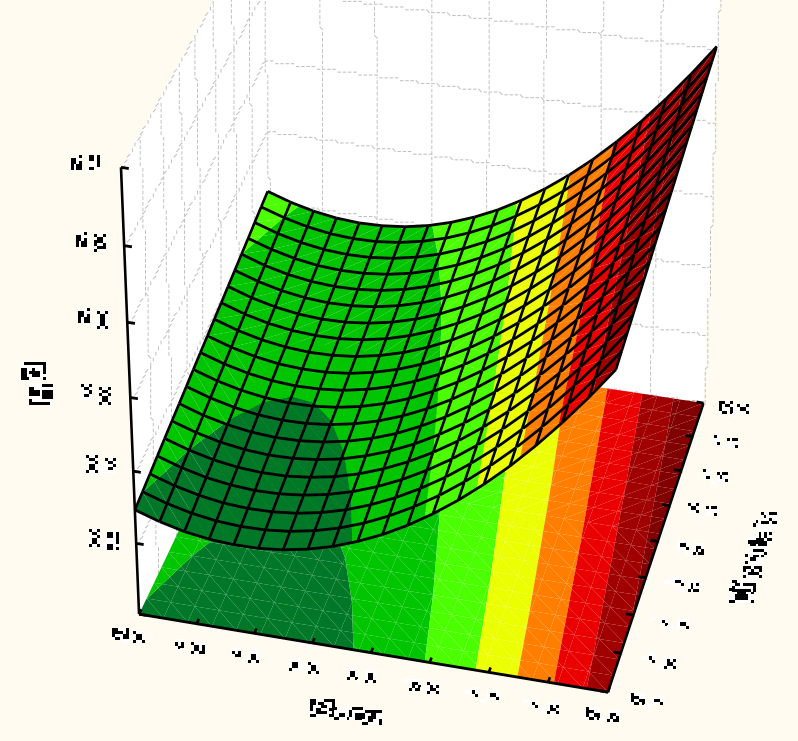

Figura 1 - Superfície de resposta de pH em sobremesas lácteas

A superfície indica que dentro da faixa de variação utilizada para a porcentagem de chocolate, sempre obtivemos os maiores valores de $\mathrm{pH}$, pois eles não variaram com as diferentes concentrações deste ingrediente, já o baru teve forte influência nestes valores. A resposta pH foi inversamente proporcional a quantidade de baru, ou seja, à medida que diminuiu a quantidade de baru chegou-se na região de maior $\mathrm{pH}$, mostrando que os pontos ótimos da resposta em questão foram nos níveis mínimos de baru.

Com relação à resposta cinza, a ANOVA mostrou que a regressão foi significativa (Fcal = $88,81$ e Ftab $=4,459)$ e a falta de ajuste não foi significativa $($ Fcal $=4,2353$ e Ftab $=19,329)$, considerando ainda que o $\mathrm{R}^{2}$ demonstrou que a variação pôde ser explicada pelo modelo $(\mathrm{Y}=$ $1,01+0,25 X_{1}+0,26 X_{2}$, sendo $X_{1}=$ chocolate $X_{2}=$ baru) e assim foi possível gerar a superfície de resposta (Figura 2). 


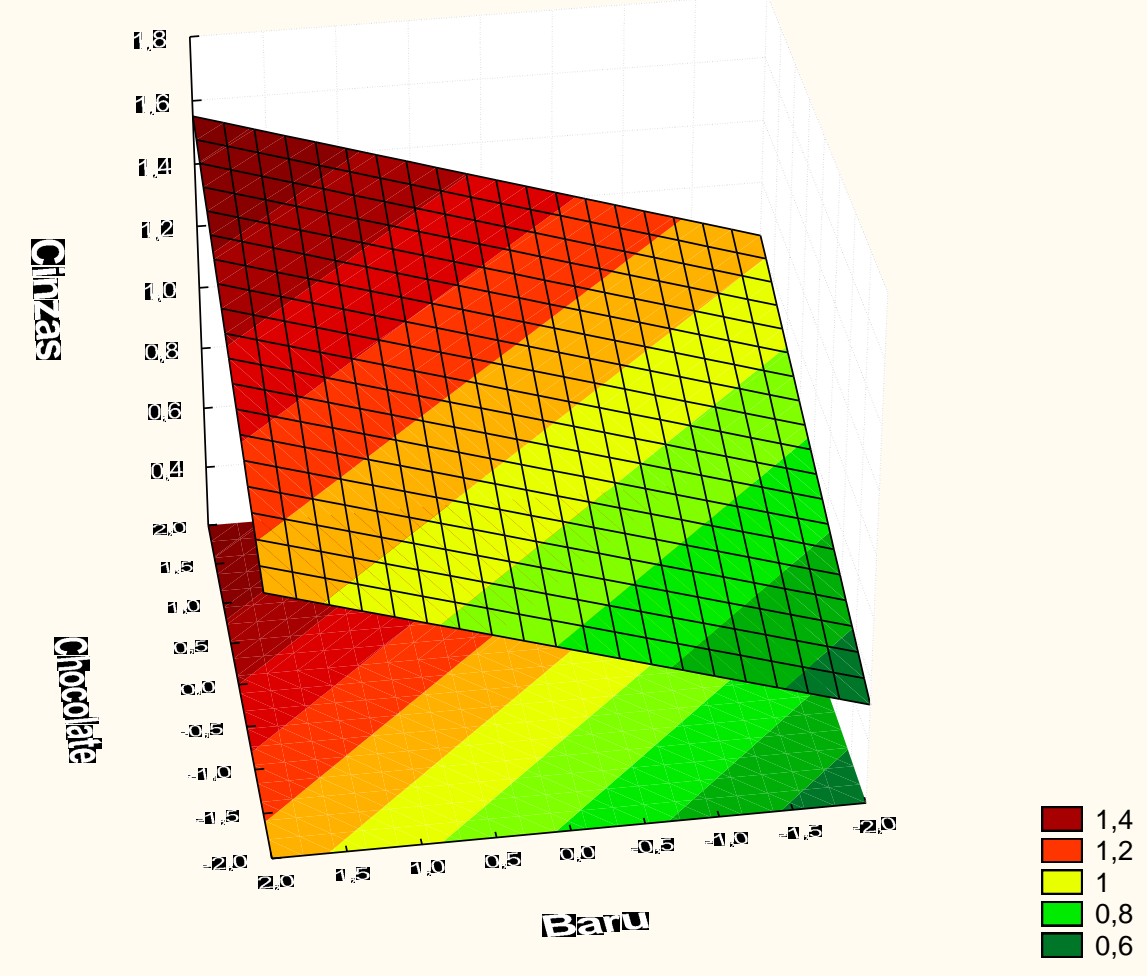

Figura 2 - Superfície de resposta de pH em sobremesas lácteas

Analisando a superfície de resposta para cinzas, nota-se que quando trabalhou-se com as maiores quantidades de baru, independente da quantidade de chocolate utilizada, maior foi o teor de cinzas encontrado nas formulações. Os níveis ótimos de cinzas se encontraram nas formulações que utilizaram os maiores teores de baru e chocolate, mostrando a influência direta destes ingredientes para este parâmetro analisado.

Para a resposta fibra, a regressão foi significativa $(\mathrm{Fcal}=52,76$ e Ftab $=4,459)$, indicando a validade do modelo experimental. No entanto, a falta de ajuste também foi significativa (Fcal $=$ 119,133 e Ftab =19,329). Entretanto, como as médias nos pontos centrais foram muito próximas e o quadrado médio do erro puro $(0,000400)$ muito baixo (razões para o F calculado da falta de ajuste ser alto), o modelo foi considerado válido para fins preditivos (Souza e Menezes, 2008).

Deste modo, obteve-se o modelo reparametrizado ou modelo reduzido $\left(\mathrm{Y}=1,42+0,4 \mathrm{X}_{1}+\right.$ $1,32 \mathrm{X}_{2}$, sendo $\mathrm{X}_{1}=$ chocolate e $\mathrm{X}_{2}=$ baru), e obteve-se também a superfície de resposta (figura $3)$. 


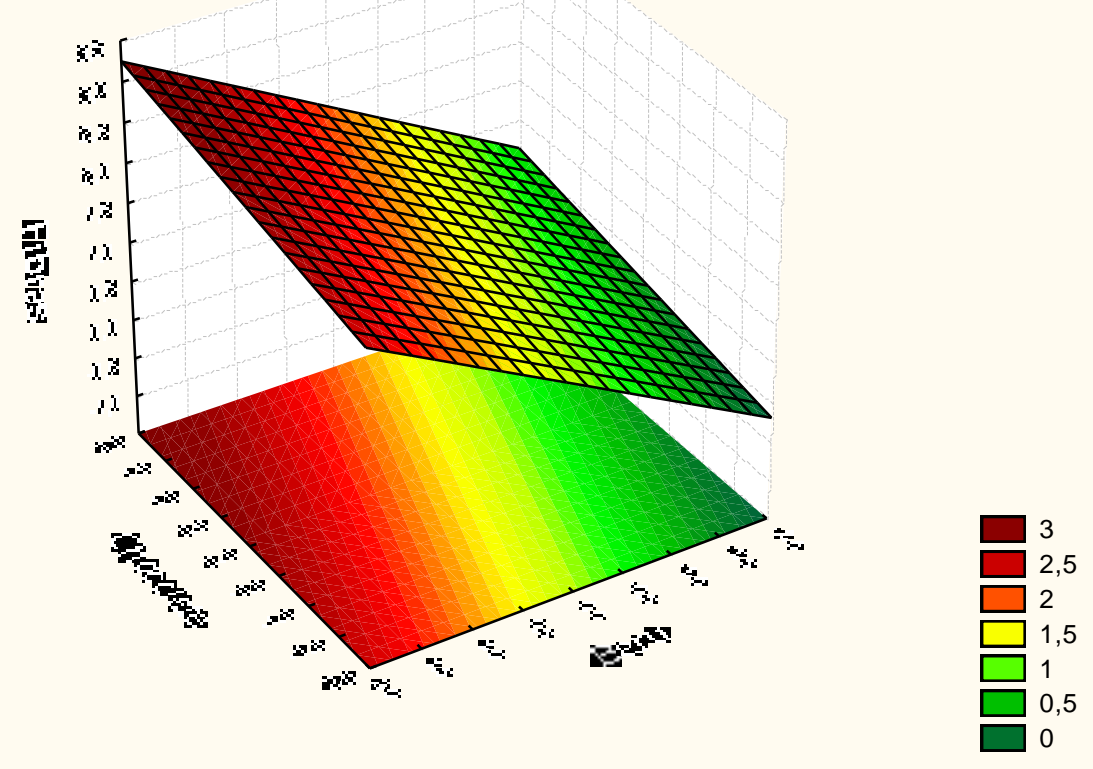

Figura 3 - Superfície de resposta de pH em sobremesas lácteas.

A superfície representa visivelmente que a variável chocolate não influenciou na resposta fibra, dentro da faixa de variação utilizada no trabalho, já o baru influenciou diretamente, assim, quanto maior a quantidade de baru nas formulações maior a quantidade de fibras. Deste modo, para se conseguir o ponto ótimo para fibras, deve-se trabalhar com a quantidade máxima de baru, independente da quantidade de chocolate.

\section{CONCLUSÃO}

Através dos resultados obtidos pode-se concluir que para as análises físico-químicas, apenas nas análises de $\mathrm{pH}$, cinzas e fibras as concentrações de chocolate e amêndoa do baru apresentaram efeitos significativos. Obtendo-se os maiores teores, ao se trabalhar com a maior quantidade de chocolate e amêndoa nas sobremesas. Sendo assim, a formulação com $14 \%$ de chocolate e 7\% de baru, é a melhor opção pois, corresponde bem as expectativas das análises realizadas. 


\section{REFERÊNCIAS}

HENRIQUE, J. R. et al. Caracterização físico-química e avaliação sensorial de sobremesa láctea tipo mousse enriquecida com casca de maracujá do cerrado. In: II Semana de Ciência e Tecnologia do IFMG, 2009, Bambuí, MG, pg. 1-5.

HENRIQUE, J. R. et al Utilização de maracujá integral no desenvolvimento de sobremesa láctea (flan) e avaliação de suas características físico-químicas e sensorial. In: II Semana de Ciência e Tecnologia do IFMG, 2009, Bambuí, MG, pg. 1-5.

NIKAEDO, P.H.L., AMARAL, F.F., PENNA, A.L.B. Caracterização tecnológica de sobremesas lácteas achocolatadas cremosas elaboradas com concentrado protéico de soro e misturas de gomas carragena e guar. Revista Brasileira de Ciências Farmacêuticas, vol.40, n.3, São Paulo, 2004.

NUNES, M.C. et al. Avaliação das sobremesas lácteas: características que podem comprometer a garantia de qualidade. Revista Higiene Alimentar, vol.12, nº 58, pag. 41-48, 1998.

SANTANA, A. T. M. C. Iogurte à base de pitaia (hylocereus undatus), enriquecido com quinoa (Chenopodium quinoa) e sucralose: desenvolvimento, aceitação e caracterização. 2011. 60f Monografia ( em Engenharia de Alimentos)-Universidade Federal de Mato Grosso, MT, 2011.

SOLER, N. et al. elaboração, composição química e avaliação sensorial de sobremesas lácteas achocolatadas com abacate. Alim. Nutr., Araraquara, v. 22, n. 1, p. 143-148, jan./mar, 2011.

SOUZA, M.L., MENEZES, H.C. Otimizacao do processo de extrusao termoplastica da mistura castanha do Brasil com farinha de mandioca. Ciência e Tecnologia de Alimentos. Campinas, v. 28, n.3, p. 659-667, julho/setembro. 2008.

OLIVEIRA SOUSA, A. G. et al. Nutritional quality ande protein value of exotics almonds and nut from de Brazilian Savanna compared to peanut. Food Research International. v. 44, n.7, p.2319-2325, 2011. 